University of Wollongong

Research Online

Faculty of Engineering and Information

Faculty of Engineering and Information

Sciences - Papers: Part B

Sciences

2019

Protecting PFC capacitors from overvoltage caused by harmonics and system resonance using high temperature superconducting reactors

Md Minarul Islam

University of Wollongong, mmi818@uowmail.edu.au

Danny Sutanto

University of Wollongong, soetanto@uow.edu.au

Kashem M. Muttaqi

University of Wollongong, kashem@uow.edu.au

Follow this and additional works at: https://ro.uow.edu.au/eispapers1

Part of the Engineering Commons, and the Science and Technology Studies Commons

Research Online is the open access institutional repository for the University of Wollongong. For further information contact the UOW Library: research-pubs@uow.edu.au 


\title{
Protecting PFC capacitors from overvoltage caused by harmonics and system resonance using high temperature superconducting reactors
}

\author{
Abstract \\ Shunt capacitors are deployed for power factor correction (PFC) to reduce the load reactive power and to \\ provide voltage support. Nonlinear loads, such as variable speed drives, can inject harmonics into the \\ network. If the line impedance value produces a resonance with the PFC capacitor and the injected \\ frequency coincides with the resonant frequency, an overvoltage is produced across the capacitor, which \\ can lead to failure or explosion. To protect the PFC capacitor, a reactor can be connected in series with \\ the PFC capacitor and tuned at the harmonic frequency of the system resonance. This paper proposes \\ the use of a high temperature-superconducting reactor (HTSR) as the tuned reactor. The reactor will have \\ an extremely high-quality factor (Q) compared to the normal reactor that can never be manufactured \\ commercially with such a high Q. The performance of the HTSR reactor in terms of its ability to protect \\ the capacitor from overvoltage and to reduce power losses has been investigated. The results are \\ compared with those using the conventional (low Q) reactor and show that the HTSR can significantly \\ improve filter performance and reduce power losses in the filter.

\section{Disciplines} \\ Engineering | Science and Technology Studies

\section{Publication Details} \\ M. Islam, D. Sutanto \& K. M. Muttaqi, "Protecting PFC capacitors from overvoltage caused by harmonics \\ and system resonance using high temperature superconducting reactors," IEEE Transactions on Applied \\ Superconductivity, vol. 29, (2) pp. 5601705-1-5601705-5, 2019.
}




\title{
Protecting PFC Capacitors from Overvoltage Caused by Harmonics and System Resonance Using High Temperature Superconducting Reactors
}

\author{
M. M. Islam, Member, IEEE, D. Sutanto, Senior Member, IEEE, and K. M. Muttaqi, Senior Member, IEEE
}

\begin{abstract}
Shunt capacitors are deployed for power factor correction (PFC) to reduce the load reactive power and to provide voltage support. Nonlinear loads, such as variable speed drives (VSD), can inject harmonics into the network. If the line impedance value produces a resonance with the PFC capacitor and the injected frequency coincides with the resonant frequency, an overvoltage is produced across the capacitor, which can lead to failure or explosion. To protect the PFC capacitor, a reactor can be connected in series with the PFC capacitor and tuned at the harmonic frequency of the system resonance. This paper proposes the use of a high temperature-superconducting reactor (HTSR) as the tuned reactor. The reactor will have an extremely high-quality factor $(Q)$ compared to the normal reactor that can never be manufactured commercially with such a high $Q$. The performance of the HTSR reactor in terms of its ability to protect the capacitor from overvoltage and to reduce power losses has been investigated. The results are compared with those using the conventional (low Q) reactor and show that the HTSR can significantly improve filter performance and reduce power losses in the filter.
\end{abstract}

Index Terms-Capacitor overvoltage protection, HTS reactor, Passive filter, Parallel resonance, Power loss in tuned filter.

\section{INTRODUCTION}

$\mathbf{P}$ OWER factor correction (PFC) capacitors are used in industrial plants to improve power factor and to support voltage. It is well known that an overvoltage may lead to capacitor failure and an excessive voltage can lead to capacitor explosion [1]. Many real case examples of PFC capacitor failure have been reported in [2] - [5]. The failure can be caused by (i) switching events and faults [6], (ii) problems in the capacitor bank switching control board [11], and (iii) a parallel resonance between the PFC capacitor and the system line inductance [7] - [10]. The excessive voltage across the PFC capacitor imposed by those events can exceed its allowable contingency continuous overload limits [12] - [14].

Parallel resonance has been documented as the main cause of such failures [3] - [9]. This occurs due to the continuously varying system impedance as lines, switched reactors, and

Manuscript received October 1, 2018; accepted January 15, 2019. This work was supported by the Australian Research Council. (Corresponding author: $M d$. Minarul Islam.)

The authors are with the Australian Power Quality and Reliability Center, School of Electrical, Computer and Telecommunications Engineering, University of Wollongong, Wollongong, NSW, 2522, Australia. (e-mail: mmi818@ uowmail.edu.au; soetanto@uow.edu.au; kashem@uow.edu.au).

Color versions of one or more of the figures in this paper are available online at http://ieeexplore.ieee.org.

Digital Object Identifier 10.1109/TASC.2019.2895269 varying loads are switched in and out [9]. Further, power electronics loads, such as rectifiers, variable frequency drive, and adjustable speed drives in the grid produce huge harmonics, which can cause poor power quality. Furthermore, when the line impedance resonates with the PFC capacitor, an injected harmonic current at exactly the same resonant frequency can amplify the voltage across PFC capacitors, that can cause the tripping or explosion of the capacitor [2] - [5]. Due to its randomness, these events had been a mystery to the PFC capacitor owners. It is difficult to predict when the parallel resonance will form, but it is important that the PFC capacitor be protected against such an event.

In [15], a hybrid anti-resonance system is proposed to shift the parallel resonant frequency from the frequency of the injected harmonic. The most effective method to achieve this is the use of passive tuned filters. Adding a series reactor with the existing PFC capacitor can form a tuned filter. All reactors will have resistances, which cause power losses [16]. The reactor's resistance is defined by its $\mathrm{Q}$. The $\mathrm{Q}$ of the reactor is defined as the ratio of its reactance at the tuned frequency to its resistance. The higher the value of $\mathrm{Q}$ is, the better is the quality of the reactor and the lesser is the loss. A reactor with a Q between 40 and 100 can be purchased from the market. A reactor with a higher value will not only cost more, but it may not be available commercially. Furthermore, the higher the Q of the reactor in a passive tuned filter is, the more the bandwidth of tuned filter is reduced, such that the tuned circuit becomes sharper and the resonance width is more reduced.

Recently, a High Temperature superconductor (HTS) reactor with almost zero resistance has been manufactured. In [17] - [21], the features of a typical HTSR including physical parameters, electro-magnetic properties, and operating temperature are described. In [22], it is suggested that a cryogenic cooling system is required in an HTSR to handle the temperature. The Q of the HTSR will be extremely high. Significant benefits of using the HTSR in a tuned filter can be obtained, such as low power losses, better tuned filter and better shifting of the parallel resonance frequency from the frequency of the injected harmonic. A comprehensive literature review has shown that no paper has reported this potential novel application of a HTSR in a tuned filer.

This paper investigates the potential benefits of using the HTSR to protect the PFC capacitor from overvoltage due to harmonics and system resonance. The main contribution of this paper is the recognition that the use of HTSRs in passive 

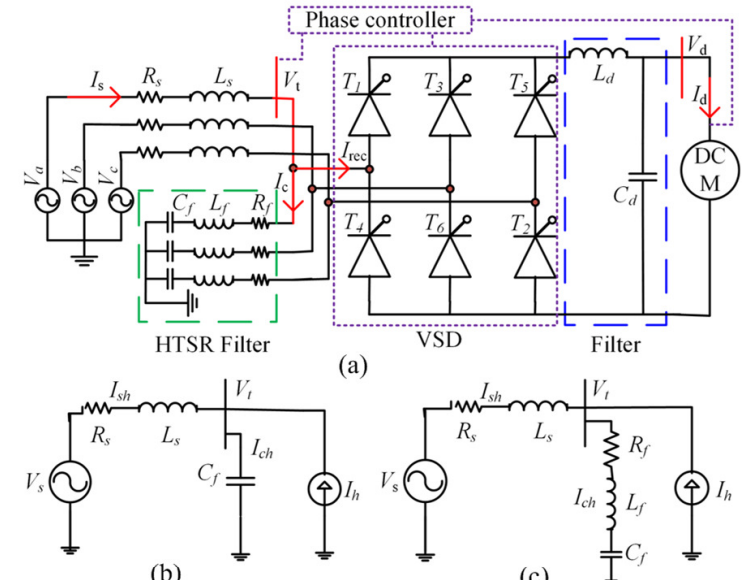

(b)
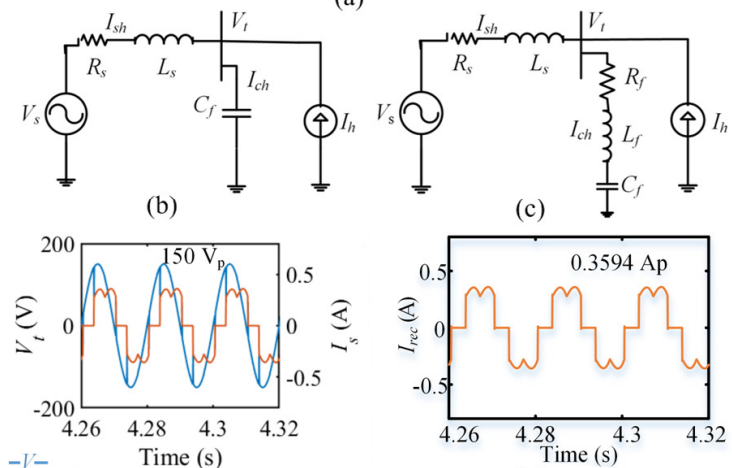

(d)

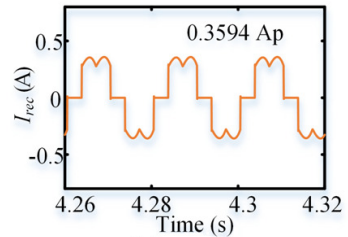

(e)

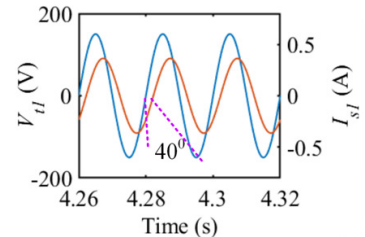

(f)

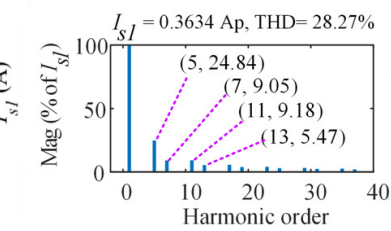

(g)
Fig. 1. (a) Test system, (b) \& (c) equivalent circuit, (d) Terminal voltage $\left(V_{t}\right)$, and Source current $\left(I_{s}\right)$, in phase- $a$ without PFC and filter (e) Rectifier current $\left(I_{r e c}\right)$, (f) $50 \mathrm{~Hz}$ components of $V_{t}$ and $I_{s}$, (g) FFT of $I_{s}$.

tuned filters can produce significant benefits in terms of lower losses, better filtering and the ability to mitigate overvoltage in PFC capacitors that can lead to a failure or explosion.

\section{PRoblem Statement of PARALlel ResonAnCE AND ITS FILTERING}

The input current in a typical industrial application of a VSD produces a phase displacement between the fundamental voltage and current leading to a low displacement power factor (DPF), which may not be acceptable by the power utility. A PFC capacitor will be required to improve the DPF and for voltage support. Further, passive tuned filters will need to be installed to reduce harmonics produced by VSD. The PFC capacitor is usually used for the harmonic filter.

Fig. 1(a) shows the test system that comprises a three-phase variable power supply connected to a nonlinear load, in the form of a VSD supplying a dc motor with a rating of $175 \mathrm{~W}$, $220 \mathrm{~V}, 1500 \mathrm{rpm}$ and the HTSR tuned filter. The VSD is used to control the speed of the dc motor at around $1200 \mathrm{rpm}$. At first, the test system in Fig. 1(a) without the HTSR is simulated using MATLAB Simulink. The parameters, based on the available LabVolt training system in the laboratory, are summarized in Table I.

Fig. 1(d) shows the terminal voltage $\left(V_{t}\right)$ and the source current $\left(I_{s}\right)$ in phase $a$. Fig. 1(f) shows the phase displacement between the fundamental components of $V_{t}$ and $I_{s}$ as $40^{\circ}$.
TABLE I

SYSTEM PARAMETERS

\begin{tabular}{lc}
\hline \hline \multicolumn{1}{c}{ Parameters } & Values \\
\hline Power Supply & $108 \mathrm{~V} / \mathrm{phase}, 50 \mathrm{~Hz}$ \\
DC motor rating & $175 \mathrm{~W}, 220 \mathrm{~V}, 1500 \mathrm{rpm}$ \\
PFC capacitor, $C_{\mathrm{f}}$ & $0.66 \mu \mathrm{F}$ \\
Reactor inductance, $L_{\mathrm{f}}$ & $0.614 \mathrm{H}$ (for $5^{\text {th }}$ harmonic filter) \\
Reactor resistance, $R_{\mathrm{f}}$ & $10 \Omega$ \\
Reactor quality factor, $Q$ & 96.4 \\
\hline
\end{tabular}

Therefore, the DPF is $\cos \left(40^{\circ}\right)=0.766$ lagging. This DPF will be unacceptable to the power utility, which will require the installation of a PFC capacitor. The rectifier current, shown in Fig. 1(e), is the same as $I_{s}$, and contains dominant low order harmonics (such as $5^{\text {th }}, 7^{\text {th }}, 9^{\text {th }}, 11^{\text {th }}$ and $13^{\text {th }}$, etc.), which are obtained by the Fast Fourier Transform (FFT) as shown in Fig. $1(\mathrm{~g})$. The total harmonic distortion (THD) of $I_{s}$ is also very high, almost $28.27 \%$, which may not be acceptable to the power utility. The per phase apparent power for the VSD is calculated from $V_{t \mathrm{rms}}$ and $I_{\text {srms }}$ and found as $27.56 \mathrm{VA}$. Its per phase reactive power requirement due to its DPF is also calculated and found as $17.72 \mathrm{VAr}$. To provide this reactive power, a $0.66 \mu \mathrm{F}$ is connected in shunt with the VSD, and the firing angle is controlled to maintain acceptable DPF.

The VSD can be considered as an injected harmonic current source as shown in Fig. 1(b), where $V_{s}$ is assumed to be a balanced three-phase source operating at $50 \mathrm{~Hz}$. Since the source contains no harmonic voltages, the PFC capacitor, $C_{f}$, is in parallel with $Z_{s}$ and can resonate at the natural frequency, $f_{n}$, which can be defined by equation (1):

$$
f_{n}=\frac{1}{2 \pi} \sqrt{\frac{1}{L_{s} C_{f}}-\left(\frac{R_{s}}{L_{s}}\right)^{2}}
$$

Any harmonic frequency equal to $f_{n}$ will cause a high impedance, close to $\infty$, of the parallel circuit, and a small harmonic current can cause a significant overvoltage across the capacitor. To solve this problem, a reactor $L_{f}$ in series with $C_{f}$, shown in Fig. 1(c), can be tuned to the harmonic frequency. $R_{f}$ is the internal resistance of the reactor. The value of the reactor inductance can be obtained using equation (2), where $\omega_{h}$ corresponds to the harmonic frequencies.

$$
L_{f}=\frac{1}{\omega_{h}^{2} C_{f}}
$$

\section{SimUlation Results}

In this paper, three case studies have been investigated. Firstly, the system has no parallel resonance at any of the injected harmonics with the reactor in series with the capacitor tuned at $5^{\text {th }}$ harmonic. Secondly, a parallel resonance occurs between the system and the PFC capacitor at the $5^{\text {th }}$ harmonic without the tuned reactor. Finally, the impact of introducing the tuned reactor on the parallel resonance at the $5^{\text {th }}$ harmonic frequency is investigated. The impact of using the HTSR with almost zero resistance is assessed in terms of its ability (a) to reduce power loss, (b) to improve filtering and (c) to shift the parallel resonance frequency from the frequency of the injected harmonic. The results have been compared with those using the commercial reactor with $Q$ of 96.4 . 


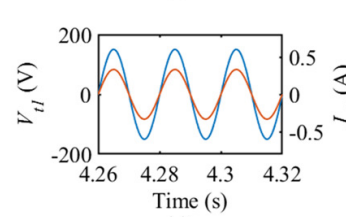

(a)

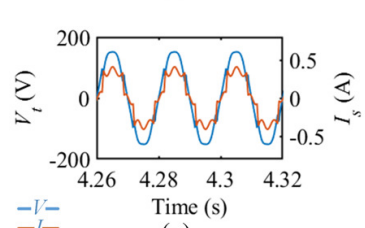

(c)

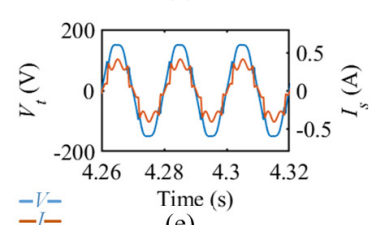

(e)

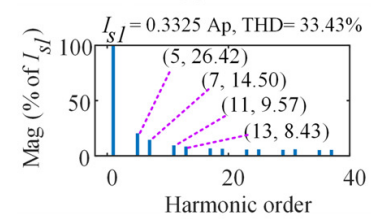

(b)

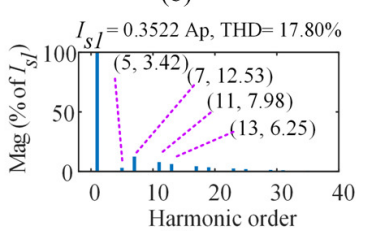

(d)

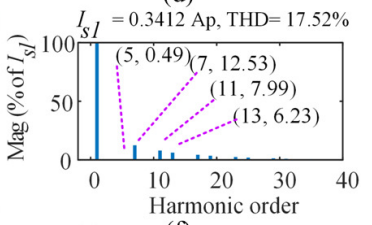

(f)
Fig. 2. (a) $50 \mathrm{~Hz}$ components of Terminal voltage $\left(V_{t}\right)$ and Source current $\left(I_{s}\right)$ with PFC capacitor, (b) FFT of $I_{s}$ with PFC capacitor, (c) $V_{t}$ and $I_{s}$ after the filter with $Q=96.4$ (d) FFT of $I_{s}$. after the filter with $Q=96.4$, (e) $V_{\mathrm{t}}$ and $I_{s}$ after the filter with Q $=10000$ (f) FFT of $I_{s}$ after the filter with Q $=10000$

\section{A. Impact of Adding PFC Capacitor to a System}

The PFC capacitor is connected in shunt with the VSD to reduce its reactive power requirement. Simulations have been carried out on the test system shown in Fig. 1(a). Fig. 2(a) shows fundamental components of the terminal voltage $\left(V_{t}\right)$ and the source current $\left(I_{s}\right)$ which are almost in phase. The $I_{s}$ is affected by the introduction of the PFC capacitor with slightly elevated harmonic current, as shown in Fig. 2(b), as some harmonic currents are now flowing through the PFC capacitor. $I_{\text {rec }}$ is found to be same as in Fig 1(e), as the addition of the PFC capacitor does not alter the operation of the rectifier.

\section{B. Impact of making the PFC capacitor a tuned filter}

A reactor $\left(L_{f}=0.614 \mathrm{H}, R_{f}=10 \Omega\right)$ with $Q$ factor of $96.4(\mathrm{Q}=$ $\left.\omega_{h} L_{f} / R_{f}=314 \times 5 \times 0.614 / 10=96.4\right)$, is connected in series with the PFC capacitor to form a tuned passive filter which is tuned to $5^{\text {th }}$ harmonic. Fig. 2(c) shows that $I_{s}$ and $V_{t}$ are still in phase. The $5^{\text {th }}$ harmonic of $I_{s}$, as shown in Fig. 2(d) is greatly reduced due to the filter action, but the other harmonics generated from the nonlinear load remain same. The tuned reactor with $\mathrm{Q}$ of 96.4 is then replaced by the HTSR coil with Q of 10000 , where the resistance is now calculated to be $0.0964 \Omega$. Fig. 2(e) shows $V_{t}$ and $I_{s}$, which are similar to those in Fig. 2 (c). Fig. 2(f) shows the FFT of $I_{s}$ with the new reactor, and it shows that with $\mathrm{Q}=10000$, the $5^{\text {th }}$ harmonic component is reduced by more than $86 \%$ compared to that with $Q=96.4$.

\section{Impact of the Fifth Harmonic Parallel Resonance}

The source impedance is designed to form a parallel resonance with the PFC capacitor at the fifth harmonic. The parallel resonance causes the peak voltage to be $538.8 \mathrm{~V}$, which is 3.59 times greater than the PFC capacitor with normal operating voltage, and this can lead to a capacitor failure or a capacitor explosion. The $V_{t}$ and $I_{s}$ have become distorted as shown in Fig. 3(a). The VSD can no longer

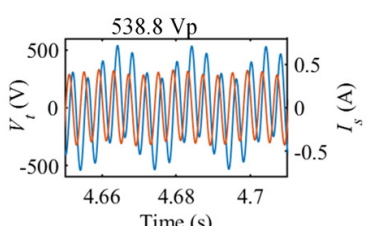

(a)

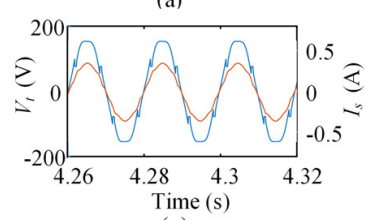

(c)

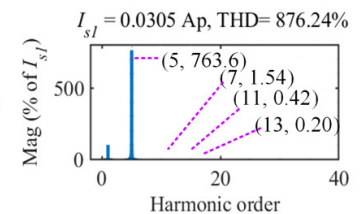

(b)

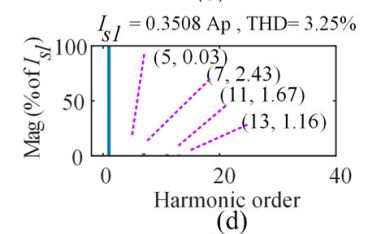

(d)
Fig. 3. (a) Source terminal voltage $\left(V_{t}\right)$, and Source current $\left(I_{s}\right)$ at parallel resonance, (b) FFT of $I_{s}$ at parallel resonance, (c) $V_{t}$ and $I_{s}$ after the filter with $Q=10000$ (d) FFT of $I_{s}$ after the filter with $Q=10000$.

capable of controlling speed of the dc motor load. Fig. 3(b) shows the harmonic components in $I_{s}$ are affected due to the parallel resonance, causing a very high THD of $876.24 \%$.

\section{Impact of the Fifth Harmonic Filter with Fifth Harmonic Parallel Resonance}

Fig. 3(c) shows that the fifth harmonic filter $(\mathrm{Q}=10000)$ has reduced $V_{t}$ substantially to $155 \mathrm{~V}$ peak. Because of the filtering action, the $5^{\text {th }}$ harmonic components in the $I_{s}$ have been reduced to almost zero as shown in Fig. 3(d). The rectifier current has returned to normal, which means normal operation of load, and the THD of the source current has been reduced to $3.25 \%$ as shown in Fig. 3(d).

\section{E. Comparison of Results in Different Scenario}

A comparison of $5^{\text {th }}$ harmonic voltage and currents in the system without and with filter $(\mathrm{Q}=96.4)$ has been shown in Table II. It shows that the filter has reduced the $5^{\text {th }}$ harmonic component for $I_{s}$ by $86.3 \%$, and for $V_{t}$ by $83 \%$, while $I_{c}$ is increased by $1245 \%$ and a small change is occurred in $I_{\text {rec }}$. Table II also compares that the $5^{\text {th }}$ harmonic component in $I_{s}$ reduces to negligible value with the filter having $Q=10000$. Table II also shows that, compare to normal operating value, the $5^{\text {th }}$ harmonic components due to parallel resonance are increased in $V_{t}$ by 24.82 times, in $I_{s}$ by 2.65 times, and in $I_{c}$ by 32.83 times, while $I_{\text {rec }}$ has decreased by $99.71 \%$. The excessive overvoltage across the PFC capacitor will surely damage it. One solution to this is to use of an HTSR in series with the PFC capacitor to force the $5^{\text {th }}$ harmonic current from the VSD to flow through the filter, and the system parameters reduce to acceptable limit as shown in Table II. Clearly further protection needs to be provided for the other harmonics as well; so it is envisaged that a $5^{\text {th }}$, a $7^{\text {th }}$, a $11^{\text {th }}$ harmonics passive tuned filter and a high pass filter will be required to protect the capacitor from overvoltage due to parallel resonance at the same frequency. This will further reduce the THD of the source current.

\section{F. Filter Power Loss Estimation}

To assess the loss, the power loss in the filter resistance is estimated and is found to be $0.0528 \mathrm{~W}(\mathrm{Q}=96.4)$, which is equivalent to $462.49 \mathrm{Wh}$ energy losses per year. A significant 
TABLE II

COMPARISON OF FIFTH HARMONIC COMPONENTS

\begin{tabular}{|c|c|c|c|c|c|c|}
\hline $5^{\mathrm{th}^{*}}$ & WOF $^{*}$ & $\mathrm{WF} 1^{*}$ & $\mathrm{WF} 2^{*}$ & $\mathrm{PR}^{*}$ & $\mathrm{PR}+\mathrm{WF} 1$ & $\mathrm{PR}+\mathrm{WF} 2$ \\
\hline$V_{\mathrm{t}}$ & 9.0556 & 1.5330 & 0.3332 & 224.78 & 2.13 & 1.1665 \\
\hline$I_{\mathrm{s}}$ & 0.0878 & 0.0121 & $1.67 \mathrm{E}^{-4}$ & 0.2330 & $9.05 \mathrm{E}^{-4}$ & $1.10 \mathrm{E}^{-4}$ \\
\hline$I_{\mathrm{c}}$ & 0.0071 & 0.0955 & 0.1108 & 0.2331 & 0.0788 & 0.0789 \\
\hline$I_{\mathrm{rec}}$ & 0.1056 & 0.1124 & 0.1133 & $3.10 \mathrm{E}^{-4}$ & 0.0789 & 0.1011 \\
\hline
\end{tabular}

reduction in the HTSR filter $(\mathrm{Q}=10000)$ power loss is observed. In this case, the power loss is found as $0.00051 \mathrm{~W}$, which is equivalent to $4.459 \mathrm{Wh}$ energy losses in a year.

\section{EXPERIMENTAL VERIFICATIONS}

\section{A. Experimental Setup}

To validate the performance of the filter, an experimental setup using the power electronic modules of the LabVolt training system was developed as shown in Fig. 4(a). The system parameters are the same as the parameters used for the simulation as given in Table I. The firing angles of the threephase thyristor module (used as VSD) are controlled by the firing angle control unit. The voltage and current wave shapes, and their harmonic contents are observed using the LabVolt Data Acquisition and Control for Electromechanical Systems (LVDAC-EMS). The power is analysed with a power analyser (PowerXplorer-DRANETZ-BMI).

\section{B. Fifth Harmonic Filtering}

Fig. 4(b) shows the terminal voltage $\left(V_{t}\right)$ and the source current $\left(I_{s}\right)$ in phase $a$ with the filter. The measured DPF is 0.756 lagging. The $I_{s}$ contains the dominant low order harmonics (such as $5^{\text {th }}, 7^{\text {th }}, 9^{\text {th }}, 11^{\text {th }}$ and $13^{\text {th }}$, etc.), as shown in Fig. 4(d). The measured THD of $I_{s}$ is $27.5 \%$, which is similar to the simulation result shown in Fig. 1(g). Fig. 4(c) shows the waveforms of $I_{s}$ and $V_{t}$ after a $5^{\text {th }}$ harmonic filter of $\mathrm{Q}=96.4$ is connected in the system. Now the DPF is 0.992 lagging, which is improved by the PFC capacitor. Fig. 4(e) shows that the $5^{\text {th }}$ harmonic is reduced by $85.4 \%$, which is comparable to the simulated results shown in Fig. 2(d). Therefore, the experimental results validate the simulated results. An HTS coil with a resistance of $1 \mu \Omega$ [21] (Q > 10000) is currently being constructed and based on the above experimental results, it is expected that better results can be obtained than those shown in Figs. 3(c) \& 3(d), and Table II.

\section{CONCLUSION}

This paper investigates the benefits of applying HTSR to protect the PFC capacitor from overvoltage due to harmonics and system resonance. The results from the simulation show that the HTSR would greatly help in the design of the tuned filter. The use of HTSR will significantly reduce the impact of a parallel resonance between the PFC capacitor and the system inductance. Further, the HTSR with a very low resistance could reduce significantly the power loss, improve the tuned filter performance and protect the PFC capacitor from the overvoltage due to system resonance. It is to be noted that the simulated system is very small and therefore the power loss reduction is quite small, but for an actual industrial application
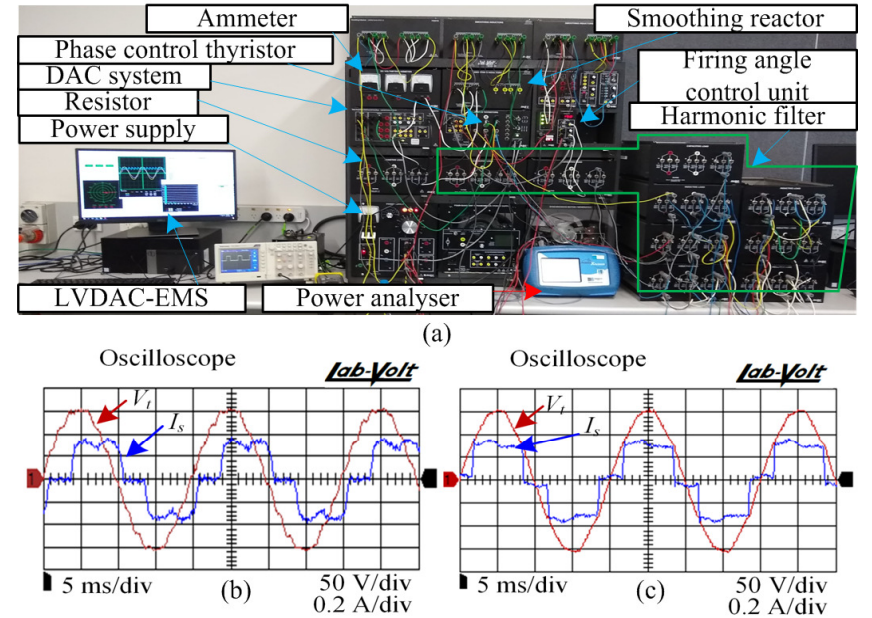

Oscilloscope

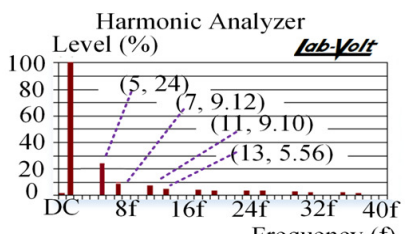

(d) Frequency (f)
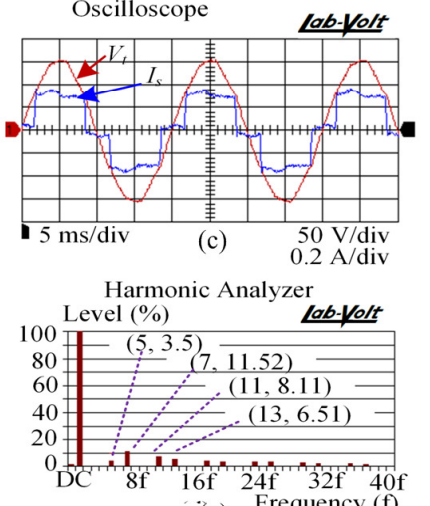

(e)

(e) Frequency (f)

Fig. 4. (a) Experimental setup, (b) Source terminal voltage $\left(V_{t}\right)$, and source current $\left(I_{s}\right)$ without tuned filter, (c) $V_{t}$ and $I_{s}$ with tuned filter, (d) harmonics in $I_{s}$ without filter, (e) harmonic in $I_{s}$ with filter.

where the load is in MW range, therefore it is expected that a significant reduction in power loss can be achieved by the use of HTSR that will provide a substantial economic savings. Also, the Q value of the HTSR can be much higher than the chosen value (10000) used in this study. A small-scale experimental setup using the LabVolt training system was developed in the laboratory. A conventional reactor module is used as the tuned reactor with a $\mathrm{Q}$ factor of 96.4. The observed results from the experimental setup validate the simulation performance of the filters. An HTS coil with a resistance of $1 \mu \Omega(\mathrm{Q}>10000)$ is currently being constructed and based on the above experimental results, it is expected that better results can be obtained than those shown in Fig. 8 and Table II.

\section{REFERENCES}

[1] L. Tang, R. Zavadil, "Shunt capacitor failures due to windfarm induction generator self-excitation phenomenon," IEEE Trans. on Energy Conversion., vol. 8, no. 3, pp. 513-519, Sep. 1993.

[2] R. L. Almonte and A. W. Ashley, "Harmonics at the utility industrial interface: A real world example," IEEE Trans. Ind. Appl., vol. 31, no. 6, pp. 1419-1426, Nov./Dec. 1995.

[3] T. J. Dionise and V. Lorch, "Harmonic filter analysis and redesign for a modern steel facility with two melt furnaces using dedicated capacitor banks," in Proc. IEEE-IAS Annu. Meeting, pp. 137-143, Conference Record, 8-12 Oct, 2006.

[4] E. J. Currence, J. E. Plizga, and H. N. Nelson, "Harmonic resonance at a medium-sized industrial plant," IEEE Trans. Ind. Appl., vol. 31, no. 4, pp. 682-690, Jul./Aug. 1995.

[5] J. K. Phipps, J. P. Nelson, and P. K. Sen, "Power quality and harmonics on distribution system," IEEE Trans. Ind. Appl., vol. 30, no. 2, pp. 476484, Mar./Apr. 1994.

[6] J. A. Bonner, W. M. Hurst, R. G. Rocamora, R. F. Dudley, M. R. Sharp, J. A. Twiss, "Selecting ratings for capacitors and reactors in applications involving multiple single-tuned filters," IEEE Trans. on Power Delivery, vol. 10, no. 1, pp. 547-555, Jan. 1995.

[7] IEEE Recommended Practice and Requirements for Harmonic Control in Electric Power Systems, IEEE Std. 519-3014 (Revision of IEEE Std. 519-1993), Jun. 11, 2014. 
[8] Jinwei He, Yun Wei Li, Ruiqi Wang, Chenghui Zhang, "Analysis and mitigation of resonance propagation in grid-connected and islanding microgrids," IEEE Trans. on Energy Conversion, vol. 30, no. 1, pp. 7081, Mar. 2015.

[9] Chen Xu, Ke Dai, Xinwen Chen, Li Peng, Yuxiao Zhang, and Ziwei Dai, "Parallel resonance detection and selective compensation control for SAPF with square-wave current active injection," IEEE Trans. on Industrial Electronics, vol. 64, no. 10, pp. 8066-8078, Oct. 2017.

[10] H. Akagi, H. Fujita, and K. Wada, "A shunt active filter based on voltage detection for harmonic termination of a radial power distribution line," IEEE Trans. on Industrial Appl., vol. 35, no. 3, pp. 638-645, Jun. 1999.

[11] T. M. Blooming, "Capacitor failure analysis: A troubleshooting case study," Cement Industry Technical Conference, pp. 345 - 356, Conference Record, 15-30 May 2005.

[12] IEEE Standard for Shunt Power Capacitors, IEEE Std. 18-2012 (Revision of IEEE Std 18-2002), Feb. 15, 2013

[13] IEEE Guide for Application of Shunt Power Capacitors, IEEE Std 10362010 (Revision of IEEE Std 1036-1992), Jan. 17, 2011.

[14] B. Badrzadeh, "Transient recovery voltages caused by capacitor switching in wind power plants," IEEE Trans. on Industry Appl., vol. 49, no. 6 , pp. 2810-2819, Dec. 2013

[15] P. Jintakosonwit, S. Srianthumrong, and P. Jintagosonwit, "Implementation and performance of an anti-resonance hybrid deltaconnected capacitor bank for power factor correction," IEEE Trans. on Power Electronics, vol. 22, no. 6, pp. 2543-2551, Nov. 2007.

[16] R. N. Beres, X. Wang, M. Liserre, F. Blaabjerg, and C. L. Bak, "A review of passive power filters for three-phase grid-connected voltage source converters," IEEE Journal of Emerging and Selected Topics in Power Electron., vol. 4, no. 1, pp. 54-69, Mar. 2016.

[17] C. Chao and C. Grantham, "Design consideration of a high-temperature superconducting magnet for energy storage in an active power filter,' IEEE Trans. Appl. Supercond., vol. 16, no, 2, pp. 612-615, Jun. 2006.

[18] Xiao Y. Chen, Jian X. Jin, Ri M. Sun, Chang L. Tang, and Yong P. Zhu, "Design and analysis of a kA-class superconducting reactor," IEEE Trans. Appl. Supercond., vol. 24, no. 5, p. 5000404 Oct. 2014

[19] C. Lee, H. Kang, K. Nam, T. K. Ko, and B.-Y. Seok, "Quench Characteristics of High Temperature Superconducting Coil for Fault Current Limiting Application", IEEE Trans. Appl. Supercond., vol. 18, No. 2, pp.632-635, Jun. 2008

[20] J. M.-Pina, N. Vilhena, P. Arsenio, A. Pronto, and A. Alvarez, "Preliminary Design and Test of Low-Resistance High Temperature Superconducting Short-Circuited Coils," IEEE Trans. Appl. Supercond., vol. 28 , no. 4, p. 4604105, Jun. 2018

[21] S.B. Kim, H. Kajikawa, H. Ikoma, J. H. Joo, J.M. Jo, Y.J. Han and H. S. Jeong, "Study on the Electrical Contact Resistance Properties With Various Winding Torques for Noninsulated HTS Coils", IEEE Trans. App. Supercond., Vol. 24, No. 3, p. 4600405, Jun. 2014.

[22] C. Chao and C. Grantham, "Design consideration of a high-temperature superconducting magnet for energy storage in an active power filter,' IEEE Trans. Appl. Supercond., vol. 16, no, 2, pp. 612-615, Jun. 2006. 